\title{
Life prospects of the unemployed: invariant and variable components in the prism of the last decade (2009-2018)
}

\author{
Irina Ralnikova ${ }^{1, *}$, and Yana Smirnova ${ }^{1}$ \\ ${ }^{1}$ Altai State University, 656049, 61 Lenin ave., Barnaul, Russia
}

\begin{abstract}
The article discusses the results of a comparison of the content and structure of life prospects of the unemployed men and women surveyed in 2009 and 2018. The study showed the specificity of the relationship of the socio-cultural context of a person's life and his/her life prospects. The invariant and variable components of the life prospects of the unemployed are revealed. Over the past ten years, a pessimistic and contradictory view of the future, a temporary orientation to a negative past and a fatalistic present, a weak eventful and targeted saturation of the future, lack of long-term planning, the existence of a conflict of time settings are invariant, which, in many respects, is a reflection of the difficulty of experiencing the absence of work. Along with the stable characteristics, transformations of the content of life planning in a situation of lack of work are revealed. The assessment of the life prospects of the unemployed, who tend to see the future as swift and useful, turned out to be varied.
\end{abstract}

Modern psychological science is concerned with the questions of changes in a person and the trajectory of his life path in response to events occurring with him. The event is interpreted in psychology as the simplest element of the life path (the life path is a series of events related to each other), which has a transforming influence on the personality (B. G. Ananyev, S. L. Rubinshtein, A. A. Kronik, L. F. Burlachuk, F. E. Vasilyuk). As signs of such a transformation is the process of rethinking a person of his past, reassessing goals, changing leading motives, changing the meaning of life. According to L. F. Burlachuk and F. E. Vasilyuk, events that depend and do not depend on the will of man, are categorized into significant and insignificant $[1,2]$. It is the subjectively significant events of the life path that bring in the noted changes of the personality-situational nature. An event that has a special subjective meaning for a person can lead to both a positive and negative perception of one's own life, determine the course of subsequent events, change one's life plans, give rise to a new way of life, change one's personality [3]. We view the lack of work as a life event that can trigger a similar transformation process. Not uncommonly, lack of work is an event that a person gives to a special status - a status of a turning point [4]. A special status in the subjective picture of the life path, the situation of blocking, personality changes, negative emotional background accompany the experience of a crucial

* Corresponding author: irinaralnikova@ yandex.ru 
event. The special status of an event is understood in terms of its subjective importance for a person in the context of the life path, the specifics of assessing the event depending on the perception and response to it, due to the personality characteristics, its experience, and the nature of the situational context [5]. The situation of blocking is associated with difficulties, sometimes irresistible character, in the implementation of human life goals, aspirations, motives, values, etc. Negative emotional background is usually expressed in feelings of fear, resentment, helplessness, despair, anger, hopelessness, etc. In general, a crucial event violates a person's self-organization, sets the context for uncertainty, "loss" of stability, and thereby determines the potential for searching for new reasons for recovery dynamic equilibrium.

In this context, the study of the life prospects of the unemployed becomes relevant, as a response to the future of the crucial situation of the present. The search for common "points" in the understanding of life prospects by different scientists (K. A. AbulkhanovaSlavskaya, E. M. Golovakha, A. A. Kronik, V. I. Kovalev, N. N. Tolstykh, R. Kastenbaum, V. Lens, J. Nutten and others) made it possible to comprehend them as a system functioning in the unity of four dimensions: value-semantic, emotional-evaluative, cognitive, organizational-activity. Unity is interpreted by us as interconnectedness and simultaneous presence of the content given by these measurements in the shape of the future. Choosing the category of "dimension", we emphasize the integrity of the system under study, the diversity of its components and manifestations. Measurement is understood as a "prism" of vision, indicates the possibility of considering this system from a certain angle of view (values, events, goals, emotions, feelings, behavior, etc.). The value-semantic dimension is defined by a set of value and semantic formations of a person, determining the individual specificity of the process and the result of designing the future (values, value orientations, motives, personal meanings). The emotional-evaluative dimension is determined by the attitude of the person to the project of their own future (emotions, feelings arising in connection with the content filling of the image of the future life). The cognitive dimension contains a set of expected and planned events (anticipated life events, goals, means of achieving goals). The organizational-activity dimension is represented by a set of styles, strategies, forms of human behavior in the present, determined by the future, reflecting the probabilistic nature of the consistent implementation of life projects into reality and the realization of their own capabilities.

We have undertaken a scientific study of the life prospects of the unemployed men and women searching for work. The main scientific interest was the comparison of ideas about the future of the unemployed being interviewed in 2009 and the unemployed being interviewed in 2018. The unemployed men and women aged 20-55 years took part in an empirical study. One group of 48 unemployed people were interviewed in 2009, another group of 27 unemployed was surveyed in 2018.

As a diagnostic tool in the study, the Zimbardo Time Persrective Inventory was used to identify factors that characterize the temporal orientation of the individual. The scale of time settings (Nuttin, Lens, Van Calster) were used to diagnose the attitude of the respondents to the future. The "Psychological autobiography" (L. F. Burlachuk, E. Yu. Korzhova) was used to study the experiences associated with the most significant life events. Mathematical-statistical processing of empirical data is presented by the procedure for calculating the criterion of difference of averages for independent samples (parametric Student's t-criterion), using the statistical package "SPSS" 23.0.

Comparison of the life prospects of the unemployed in 2009 and in 2018 made it possible to determine their invariant and variable components. An analysis of the results of diagnostics of temporary orientations of the unemployed in 2009 and 2018 showed no statistically significant differences between the compared groups, which means that over 
ten years their temporary settings have not changed. The leading ones are the orientation of the unemployed towards the negative past and the fatalistic present (Table 1).

Table 1. Temporary installation of the unemployed.

\begin{tabular}{|c|c|c|c|c|}
\hline \multirow[b]{2}{*}{ Scale } & \multicolumn{2}{|c|}{2009} & \multicolumn{2}{|c|}{2018} \\
\hline & 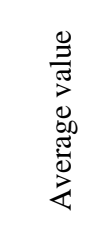 & 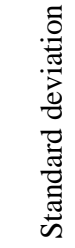 & 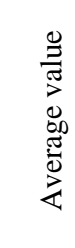 & 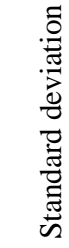 \\
\hline Negative past & 3,78 & 0,76 & 2,47 & 0,73 \\
\hline Hedonistic present & 2,066 & 0,56 & 3,10 & 0,49 \\
\hline Future & 2,33 & 0,67 & 3,87 & 0,62 \\
\hline Positive past & 2,51 & 0,66 & 3,46 & 0,50 \\
\hline Fatalistic present & 3,21 & 0,51 & 2,54 & 0,65 \\
\hline
\end{tabular}

Negative attitudes towards the past are most often the result of real traumatic and unpleasant events, or a negative reconstruction of past events involving pain and regret. The unemployed tend to negatively and pessimistically assess the events of their own past, as well as life in general, as not sufficiently pleasurable. The fatalistic attitude indicates an experience of helplessness and hopelessness in relation to the future and to life in general, a firm belief that the future is predetermined, the present must be tolerated with submission. This entails low satisfaction with life in the present and low motivation for planning the future.

At the same time, for the period from 2009 to 2018, the unemployed men and women experienced a weakening of the acuteness of the negative assessment of the past, and the fatalistic attitude towards life and the future (Table 1). Also, the unemployed, interviewed in 2018, have a more pronounced temporal orientation for the future, a positive past and a hedonistic present. So, the unemployed, despite the lack of employment and earnings, began to relate to life more positively and optimistically, which can be fixed as the variable characteristics of their life prospects.

Over the past ten years, the weak eventful saturation of the future has remained invariant. On average, the unemployed celebrate two events in their life prospects. Usually, these events are related to employment (for example, "getting a job", "making money", "helping the family financially") and the family sphere (for example, "child graduation", "wedding of friends", "conflict", "divorce"). An important fact is that the events of other life spheres are rarely present in the life prospects of the unemployed. Also, the overall assessment of future events by the unemployed, who are seen by them mostly as "joyful" (on average, 5 points on a five-point scale), did not change. At the same time, if we analyze the time continuum as a whole (past, present and future) presented in the human mind, then the fact of the presence of a lower score as positive events of the past (average 4 points on a five-point scale) and present (average 3 points on a five-point scale). In our opinion, this indicates a pronounced optimism and belief in changes for the better, sometimes bordering on reverie, unrealistic and infantile position, and possibly updating the mechanisms of psychological defense. 
Sustained remains the fact that the unemployed men and women more often plan in a short-term perspective (period up to a year), less often in a medium-term one (a period of about 1 year to 5 years) and practically do not look in the long-term (a period of five years and more). Attention of the unemployed to the near future, on the one hand, stimulates activity and directs efforts to meet actual life goals, on the other hand, leads to undifferentiated life plans, blurring the image of the future.

Returning to the invariant aspects of ideas about the life prospects of the unemployed, it should be noted that they tend to think negatively about their future and devalue the importance of this time period in their lives. The unemployed interviewed in 2009 represent the future as (average on a seven-point scale) boring $(6.02+1.27)$, useless $(5.97+1.36)$, repulsive $(5.6+$ $1.61)$, cold $(5.67+1.39)$, imposed from outside $(5.34+1.52)$, distant $(5.15+0.81)$, conflict $(4.89+1.65)$, uncertain $(4.81+1.87)$, deleted $(5+1.72)$. The unemployed investigated in 2018 see the future as useless $(6.66+0.67)$, repulsive $(6.6+0.67)$, imposed from the outside $(6.29+$ $0.86)$, cold $(6.51+0.64)$, boring $(6.40+0.79)$, distant $(4.62+2.18)$, unspecified $(5.66+1.51)$, conflicting $(5.51+1.52)$, difficult $(5.33+1.73)$. Nevertheless, despite the general negativism, with the help of the Student's t-test, significant differences in the perception of the future of the unemployed in 2009 and 2018 were revealed (Fig. 1).

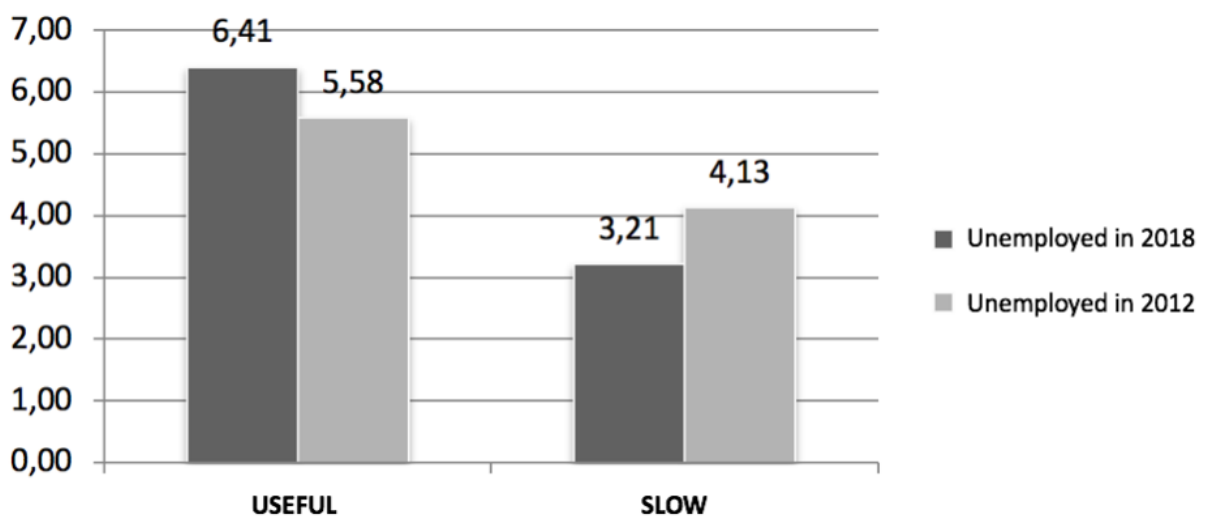

Fig. 1. Ideas about the future of the unemployed.

The unemployed in 2018 estimate the future as more useful $(\mathrm{t}=2.304, \mathrm{p}=0.025)$ and more rapid $(t=-2.270, p=0.027)$, if compared with the unemployed surveyed in 2009 .

Thus, the conducted study allowed determining steady and dynamic tendencies in the structure and content of the life prospects of the unemployed for the period from 2009 to 2018. Life prospects of the unemployed for the study period for the most part remain invariant. The nature of the temporal orientation remains unchanged, the temporal orientation towards the negative past and the fatalistic present dominates, as well as the pessimistic mood for the future, the weak eventful and targeted saturation of the future, the lack of long-term planning. Along with this, you can mark the points of possible changes. Shifts compared with 2009 are currently taking place in changing the assessment of the future of the unemployed in terms of its utility and speed characteristics. Along with the invariant and variable characteristics of life prospects, it is important to note those that we interpret them as a manifestation of conflict tendencies among the unemployed. This concerns the contradiction between the two temporary settings for the future. On the one hand, they relate to the future negatively, believing that their existence will be meaningless, the future life will not bring anything but boredom, disgust, aimlessness. On the other hand, the unemployed demonstrate over-optimism, reflecting on the future as a positive period filled with joyful events. In general, the life prospects of the unemployed are pessimistic and contradictory, reflect the complexity of their experience of the crucial event of 
"absence of work", cannot be the basis of the psychological stability of a person in search of work and entail psychological risks.

\section{References}

1. L. F. Burlachuk, E. Yu. Korzhova, Psychology of life situations (Russian Pedagogical Agency, Moscow, 1998)

2. F. E. Vasilyuk, Psychology of experiencing (analysis of overcoming critical situations) (Moscow University Press, Moscow, 1984)

3. E. S. Mazur, V. B. Gelfandg, P. V. Kachalov, Psychological Journal, 13, 2 (1992)

4. I. A. Ralnikova, Reconstruction of the system of human life prospects at the stage of crucial events (Publishing house of Altai State University, Barnaul, 2012)

5. L. I. Antsyferova, Psychological Journal, 12, 1 (1996) 